Jurnal Fokus Manajemen Bisnis
Vol.11, No.1, Maret 2021, pp.111-126
https://doi.org/10.12928//fokus.v11i1.3593
http://journal2.uad.ac.id/index.php/fokus
Universitas
Ahmad Dahlan

\title{
PENGARUH PHYSICAL EVIDENCETERHADAP KEPUTUSAN PEMILIHAN PROGRAM STUDI MANAJEMEN FAKULTAS EKONOMI DAN BISNIS UNIVERSITAS AHMAD DAHLAN
}

\author{
Suryana Hendrawan \\ Universitas Ahmad Dahlan \\ suryana.hendrawan@mgm.uad.ac.id
}

Article history

Received 2021-01-31

Revised 2021-01-27

Accepted

Keywords

Facility Exterior

Facility Interior

Other Tangibles

Purchase Decision
This study aims to analyze the factors influencing physical evidence on student decisions in choosing the Management Study Program, Faculty of Economics and Business, Universitas Ahmad Dahlan, either simultaneously or partially. This research is explanatory research with a quantitative approach. This study uses multiple analysis tests to find the partial and simultaneous effect between the dependent and independent variables. The validity and reliability used in this study have met the requirements. The results of this study indicate that facility exterior, facility interior, and other tangibles factors influencing the decision to choose the Management Study Program, Faculty of Economics and Business, Universitas Ahmad Dahlan. The result also shows that Physical Evidence Variables are simultaneously influencing the student's purchase decision the Management Study Program, Faculty of Economics and Business, Universitas Ahmad Dahlan.

This is an open-access article under the CC-BY-SA license.

\section{Pendahuluan}

Berkembangnya dunia pendidikan di Indonesia membuat beberapa lembaga pendidikan harus melakukan strategi agar tetap menjadi pilihan terbaik dari masing-masing peserta didiknya. Tuntutan perkembangan zaman yang semakin kompleks memaksa setiap orang untuk selalu mengikuti perkembangan zaman yang semakin modern dan praktis. Lembaga pendidikan yang semakin banyak tersebut membuat persaingan semakin ketat dan berlomba-lomba untuk meraih kepuasan konsumen.

Demi tercapainya kepuasan konsumen tersebut, maka lembaga pendidikan tersebut dituntut agar dapat mengerti dan memahami selera konsumen yang ada saat ini. Beragamnya produk yang ditawarkan kepada konsumen membuat konsumen lebih selektif dalam menentukan produk yang ditawarkan produsen yang sesuai dengan kebutuhan maupun harapan yang diinginkan. Lembaga perguruan tinggi merupakan perusahaan jasa dibidang layanan pendidikan yang tidak lepas dari bidikan para calon konsumennya yaitu calon mahasiswa yang nantinya akan menggunakan atau merasakan secara langsung baik tangible facility maupun intangible facility dalam sebuah kampus.

Dalam pemasaran, ada banyak sekali strategi untuk mencapai kepuasan konsumen, diantaranya adalah strategi marketing mix (bauran pemasaran) yang di dalamnya terdapat physical evidence (bukti fisik). Menurut Wulan et al., (2016) bauran pemasaran yang lebih terkhususkan pada jasa memberikan pengaruh yang positif terhadap keputusan pembelian. Ibad et al., (2018) dalam penelitiannya menyatakan bahwa physical evidence memberikan pengaruh yang positif terhadap keputusan pembelian pada studi kasus jasa transportasi CV 
King Tour and Travel. Dalam studi kasus pada Hotel Poster Bandung yang diteliti oleh Adriansyah dan Kartawinata (2014) menghasilkan bahwa dalam keputusan menggunakan jasa hotel, faktor yang berpengaruh adalah price (harga), people (orang), dan physical evidence (bukti fisik). Menurut Zeithaml dan Bitner (2000) physical evidence sendiri terdapat 3 dimensi utama yaitu facility exterior, facility interior, dan other tangibles.

Universitas Ahmad Dahlan (UAD) adalah salah satu universitas yang sudah berkembang pesat dan sudah memiliki nama yang baik di jajaran universitas terkemuka di dalam maupun di luar negeri. Semakin berkembangnya universitas dan ketatnya persaingan lembaga pendidikan strata 1 membuat penelitian ini semakin menarik untuk dianalisa apa yang menjadi dasar dalam keputusan pembelian jasa pendidikan oleh responden.

Program Studi Manajemen menjadi salah satu program studi dengan jumlah mahasiswa terbanyak di UAD. Dapat dilihat dalam gambar 1 bahwa Program Studi Manajemen selalu mengalami peningkatan setiap periodenya dalam peminatan program studi di UAD dengan jumlah 1399 mahasiswa dari totalnya 24.511 mahasiswa (Data Sistem Informasi Penerimaan Mahasiswa Baru, 2021). Semakin banyak jumlah mahasiswa dapat menggambarkan kondisi yang ada di lingkungan lembaga pendidikan strata 1 UAD.

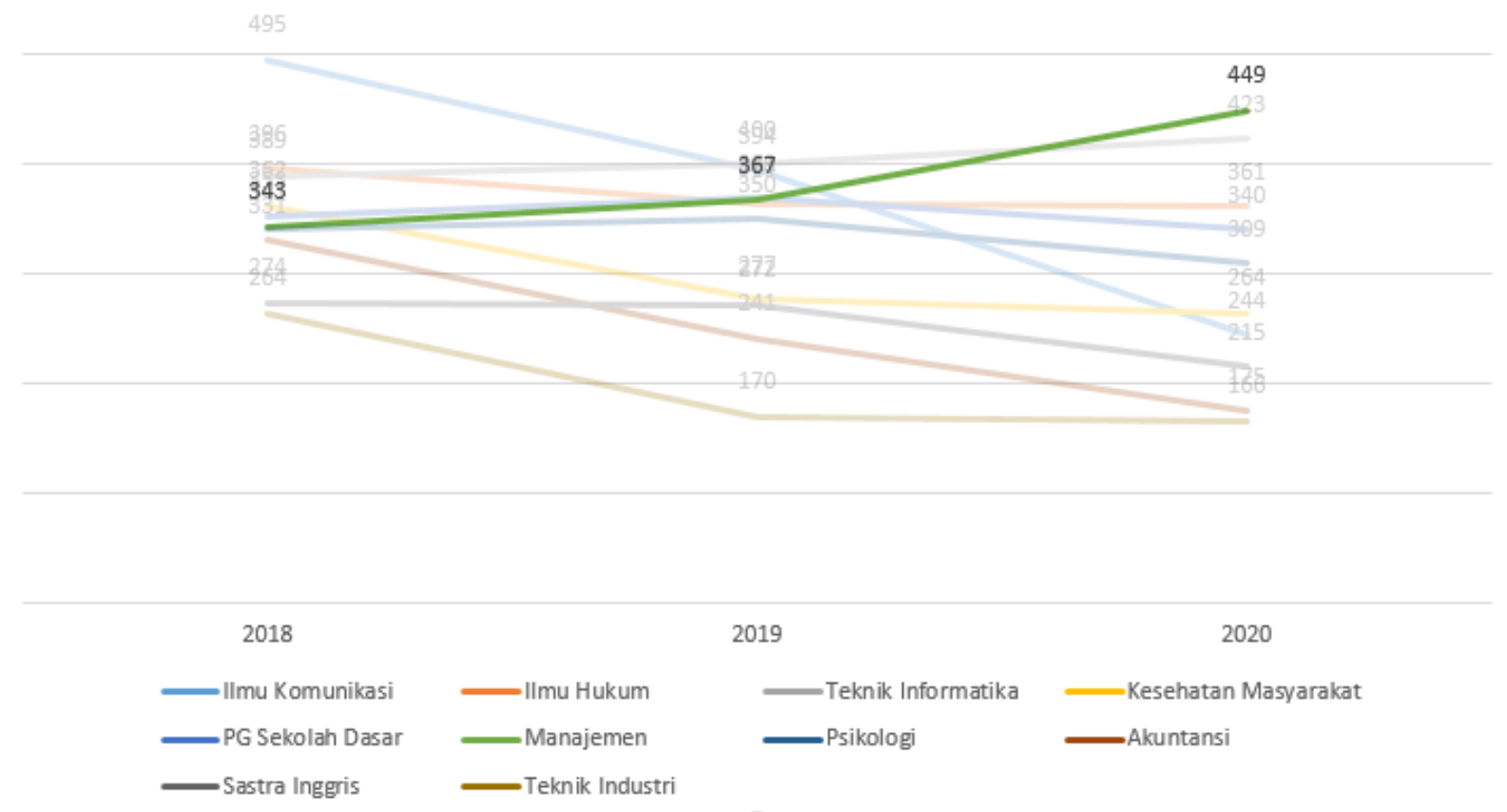

Sumber: Data Sistem Informasi Penerimaan Mahasiswa Baru (2021)

Gambar 1. Peringkat Peminatan Program Studi di UAD

\section{Review Literatur dan Hipotesis}

\subsection{Landasan Teori}

\subsubsection{Manajemen Pemasaran}

Swastha (2009) berpendapat bahwa pemasaran merupakan kegiatan yang diarahkan pada usaha untuk memuaskan keinginan dan kebutuhan melalui proses pertukaran. Manajemen pemasaran menurut Kotler dan Keller (2016) adalah seni dan ilmu memilih pasar sasaran dan mendapatkan, menjaga, dan mengembangkan konsumen melalui penciptaan, penyampaian, dan pengkomunikasian customer value. Lebih lanjut, Kotler dan Keller (2016) menambahkan bahwa dalam manajemen pemasaran, segala tindakan meliputi proses manajerial mulai dari perencanaan, pengorganisasian, pelaksanaan, dan evaluasi mulai dari penetapan produk, harga, 
distribusi, promosi, sumber daya manusia, proses, hingga bukti fisik. Tujuan manajemen pemasaran adalah mengatur tingkat atau sifat permintaan dengan cara yang dapat membantu organisasi dalam mencapai tujuan untuk mencari strategi pemasaran kompetitif yang terbaik.

\subsubsection{Bauran Pemasaran}

Menurut Kotler dan Keller (2016) bauran pemasaran adalah sekumpulan alat pemasaran yang dapat digunakan oleh perusahaan untuk mencapai tujuan pemasarannya dalam pasar sasaran. Bauran pemasaran terdiri dari 4P yaitu Product (Produk), Price (Harga), Place (Distribusi), dan Promotion (Promosi). Sedangkan untuk pemasaran jasa diperluas dengan adanya tambahan 3P yaitu People (Orang), Process (Proses), Physical Evidence (Bukti Fisik).

\subsubsection{Physical Evidence (Bukti Fisik)}

Menurut Zeithaml dan Bitner (2000) bukti fisik adalah suatu hal yang secara nyata turut mempengaruhi keputusan untuk membeli dan menggunakan produk jasa yang ditawarkan. Ada 3 dimensi utama dalam physical evidence menurut Zeithaml dan Bitner (2000) yaitu facility exterior, facility interior, dan other tangibles. Kemudian masing-masing dimensi dibagi menjadi beberapa pembagian lagi, yaitu sebagai berikut:

1. Facility exterior adalah sarana yang nampak dari luar sehingga para pengunjung dapat langsung melihat lingkungan sekitar suatu perusahaan atau gedung. Facility exterior dapat berupa:

a. Exterior design, yaitu desain atau gambaran atau tampilan luar suatu gedung termasuk hiasannya.

b. Exterior signage, yaitu setiap jenis grafik visual yang dibuat untuk menampilkan informasi kepada khalayak tertentu di luar gedung.

c. Parking, yaitu area atau lahan atau tempat yang dapat dijadikan penghentian kendaraan yang dipakai baik oleh pemilik, karyawan, atau pengunjung tertentu.

d. Landscape, yaitu pemandangan yang ada di sekitar lingkungan gedung atau kawasan tertentu.

e. Surrounding environment, yaitu keadaan lingkungan sekitar gedung bisa berupa kondisi cuaca, kondisi udara, kondisi suara, dan kondisi alam.

2. Facility interior adalah sarana yang nampak ketika pengunjung memasuki area dalam gedung. Facility interior dapat berupa:

a. Interior design, yaitu desain atau gambaran atau tampilan dalam suatu gedung termasuk hiasannya.

b. Equipment, yaitu segala peralatan yang digunakan untuk membantu memudahkan manusia dalam menyelesaikan sesuatu.

c. Interior signage, yaitu setiap jenis grafik visual yang dibuat untuk menampilkan informasi kepada khalayak tertentu di dalam gedung.

d. Layout, yaitu tata ruang yang disusun berdasarkan fungsi atau kegunaan atau keperluan.

e. Air quality/temperature, yaitu kondisi udara di dalam ruangan.

f. Sound/music/scene/lighting, yaitu kondisi suasana yang dapat mendukung emosional dari para pengunjung.

3. Other tangible adalah tampilan fisik lain yang nampak dan dapat dijadikan sebagai penguat tampilan fisik lainnya. Other tangible dapat berupa:

a. Business card, yaitu kartu tanda pengenal yang dapat dijadikan identitas seseorang.

b. Stationery, yaitu alat yang dapat dipakai untuk menulis. 
c. Billing statements, yaitu lembaran yang menyatakan ringkasan tagihan yang ditujukan kepada para konsumen.

d. Reports, yaitu laporan yang biasanya digunakan oleh beberapa pemangku kepentingan di sebuah perusahaan.

e. Employee dress, yaitu pakaian yang dikenakan oleh karyawan.

f. Uniform, yaitu pakaian yang dikenakan oleh karyawan yang memiliki kesamaan bentuk, warna, corak, atau model.

g. Brochures, yaitu lembaran yang digunakan untuk memberikan informasi mengenai produk yang ditawarkan.

h. Web pages, yaitu halaman yang ditampilkan di sebuah situs internet yang memberikan informasi terkait dengan orang atau institusi atau subjek tertentu.

\subsubsection{Keputusan Pembelian}

Keputusan dalam membeli merupakan sekumpulan keputusan yang terdiri dari keputusan tentang jenis produk, bentuk produk, merek, penjualnya, jumlah produk, waktu pembelian, dan cara pembayaran (Swastha, 2008). Kotler dan Keller (2016) berpendapat bahwa dalam proses pengambilan keputusan dalam pembelian melibatkan lima tahapan yaitu pengenalan masalah keinginan dan kebutuhan, pencarian sumber informasi, evaluasi alternatif pembelian, keputusan pembelian, dan perilaku pasca pembelian. Sedangkan dalam keputusan dalam membeli melibatkan beberapa pihak, yaitu pengambil inisiatif, orang yang mempengaruhi, pembuat keputusan pembelian, pemberi izin pembelian, pembeli, orang yang membatasi dalam hal informasi dan pembelian, dan terakhir adalah pemakai. Assauri (2004) mengemukakan bahwa keputusan pembelian adalah suatu proses pengambilan keputusan akan pembelian yang mencakup penentuan apa yang akan dibeli atau tidak melakukan pembelian dan keputusan tersebut diperoleh dari kegiatan-kegiatan sebelumnya.

\subsection{Pengembangan Hipotesis}

2.2.1. Pengaruh Positif Facility Exterior terhadap Keputusan Pemilihan Program Studi Manajemen Fakultas Ekonomi dan Bisnis Universitas Ahmad Dahlan

Bukti fisik organisasi adalah tempat produk atau jasa diciptakan, tempat penyedia produk atau jasa, tempat konsumen berinteraksi, lingkungan, ditambah unsur berwujud apapun yang digunakan untuk mendukung peranan jasa yang diberikan oleh organisasi mampu meningkatkan keputusan konsumen dalam pemilihan suatu produk atau jasa (Kotler dan Keller, 2016). Penelitian terdahulu yang dilakukan oleh Sabrilia et al., (2016) menunjukkan hasil faktor physical evidence dalam dimensi facility exterior berpengaruh positif terhadap keputusan pembelian konsumen di Happy Cow Palasari Bandung. Berdasarkan uraian tersebut, maka hipotesis pertama dalam penelitian ini adalah:

$\mathrm{H}_{1}$ : Facility Exterior Berpengaruh Positif terhadap Keputusan Pemilihan Program Studi Manajemen Fakultas Ekonomi dan Bisnis Universitas Ahmad Dahlan.

\subsubsection{Pengaruh Positif Facility Interior terhadap Keputusan Pemilihan Program Studi Manajemen Fakultas Ekonomi dan Bisnis Universitas Ahmad Dahlan}

Menurut Shimp (2014) trustworthiness dikenal sebagai pribadi yang informasinya dapat dipercaya. Kepercayaan secara konsisten memberikan apa yang telah dijanjikan. Zhao dan Tseng (2007) berpendapat bahwa facility interior yang fleksibel berpengaruh positif terhadap keputusan pembelian serta dapat meningkatkan profit dan service quality. Tatanan ruang yang dapat disesuaikan 
dengan kondisi acaranya membuat para konsumen menjadi lebih nyaman dan dapat memaksimalkan dari nilai fungsi ruangan tersebut, sehingga pada akhirnya akan mempengaruhi keputusan konsumen dalam memilih.

Hasil penelitian oleh Sarashadi dan Dewi (2018) mendapat hasil bahwa sumber kepercayaan terhadap vlogger berpengaruh positif pada sikap konsumen terhadap iklan. Hasil penelitian yang telah dilakukan oleh Irpansyah et al., (2019) mengemukakan bahwa adanya pengaruh yang positif dan signifikan antara power seorang selebgram terhadap minat beli produk mode lokal di Instagram. Berdasarkan uraian tersebut, maka hipotesis kedua dalam penelitian ini adalah:

$\mathrm{H}_{2}$ : Facility Interior Berpengaruh Positif terhadap Keputusan Pemilihan Program Studi Manajemen.

2.2.3. Pengaruh Positif Other Tangible terhadap Keputusan Pemilihan Program Studi Manajemen Fakultas Ekonomi dan Bisnis Universitas Ahmad Dahlan

Menurut Dahl et al., (2012) informasi sosial seperti laman jaringan, brosur, seragam, dan segala informasi sosial lainnya menjadi pertimbangan bagi konsumen dalam memutuskan membeli produknya. Begitu pula dengan Kopp dan Langenderfer (2014) yang berpendapat bahwa ketika sebuah perusahaan mengatur tampilan dan suasana yang mendukung di dalam gerai yang bisa ditunjukkan dengan adanya tatanan ruang, seragam, tampilan di dalam gerai dapat meningkatkan penjualan dan loyalitas konsumen sehingga dapat meningkatkan keputusan pembelian produk konsumen. Berdasarkan pendapat beberapa ahli tersebut maka dapat disimpulkan bahwa other tangible memberikan dampak yang positif terhadap keputusan pembelian. Penelitian terdahulu yang dilakukan oleh Sabrilia et al., (2016) menunjukkan hasil faktor physical evidence dalam dimensi other tangibles berpengaruh positif terhadap keputusan pembelian konsumen di Happy Cow Palasari Bandung. Berdasarkan uraian tersebut, maka hipotesis ketiga dalam penelitian ini adalah:

$\mathrm{H}_{3}$ : Other Tangible Berpengaruh Positif terhadap Keputusan Pemilihan Program Studi Manajemen Fakultas Ekonomi dan Bisnis Universitas Ahmad Dahlan.

2.2.4. Pengaruh Facility Exterior, Facility Interior, dan Other Tangible secara Simultan terhadap Keputusan Pemillihan Program Studi Manajemen Fakultas Ekonomi dan Bisnis Universitas Ahmad Dahlan

Menurut Adriansyah dan Kartawinata (2014) physical evidence (bukti fisik) memiliki pengaruh yang signifikan terhadap keputusan penggunaan jasa Hotel Posters dan juga mempunyai rasa memiliki. Hal ini juga didukung oleh Citrawati dan Sulistiono (2014) dalam analisis yang sama pada perusahaan jasa biro travel PT. Fazary Wisata Bogor. Wulan et al., (2016), Ibad et al., (2018), dan Marcelina et al., (2018) menambahkan bahwa physical evidence (bukti fisik) memberikan pengaruh yang signifikan terhadap keputusan pembelian. Berdasarkan uraian tersebut, maka hipotesis keempat dalam penelitian ini adalah:

$\mathrm{H}_{4}$ : Facility Exterior, Facility Interior, Other Tangible secara Simultan Berpengaruh Positif terhadap Keputusan Pemilihan Program Studi Manajemen Fakultas Ekonomi dan Bisnis Universitas Ahmad Dahlan. 


\subsection{Model Penelitian}

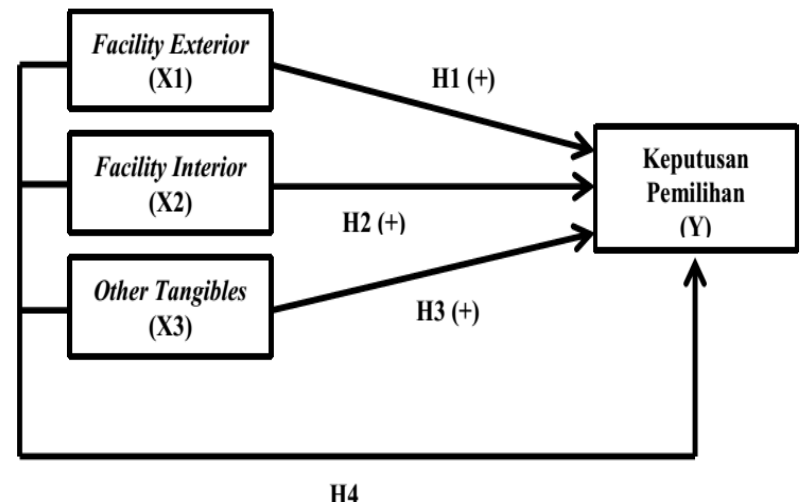

Gambar 2. Model Penelitian

\section{Metode Penelitian}

\subsection{Populasi dan Sampel}

Populasi dalam penelitian ini adalah mahasiswa aktif Program Studi Manajemen Fakultas Ekonomi dan Bisnis Universitas Ahmad Dahlan sejumlah 1399 mahasiswa. Sampel yang digunakan dalam penelitian ini diperoleh dengan metode probability sampling berjumlah 200 mahasiswa. Dalam penelitian ini digunakan simple random sampling pada mahasiswa aktif Program Studi Manajemen Fakultas Ekonomi dan Bisnis Universitas Ahmad Dahlan. Penelitian ini dilakukan mulai bulan Januari 2021 sampai dengan bulan Februari 2021.

\subsection{Metode Pengumpulan Data}

Penelitian ini menggunakan data primer sebagai sumber data. Data primer diperoleh dari menyebarkan angket (kuesioner). Kuesioner yang digunakan menggunakan skala likert dengan membuat suatu daftar pertanyaan yang akan diisi oleh responden untuk memperoleh data berupa jawaban yang akan dianalisis. Dalam kuesioner ini terdapat 2 bagian yaitu:

1. Bagian I mengisi data responden antara lain nama, jenis kelamin, umur, alamat.

2. Bagian II mengenai daftar pertanyaan yang akan di isi responden.

\subsection{Metode Analisis Data}

\subsubsection{Uji Validitas}

Menurut Misbahuddin dan Hasan (2014) uji validitas adalah suatu ukuran yang menunjukkan tingkat kesahihan suatu instrumen. Instrumen yang sahih atau valid, berarti memiliki validitas yang tinggi. Sebuah instrumen dikatakan valid apabila mampu mengukur apa yang diinginkan atau mengungkap data dari variabel yang diteliti. Uji validitas ini sangat perlu dilakukan untuk menunjukkan sejauh mana instrumen penelitian dapat mengukur objek dalam penelitian secara tepat (Cooper dan Schindler, 2011). Pengujian validitas yang digunakan adalah pengujian validitas konstruk dengan menggunakan faktor analisis. Validitas akan diketahui dengan menghitung nilai factor loading. Factor loading adalah korelasi item-item pertanyaan dengan konstruk yang diukur. Menurut Hair et al., (2011) suatu instrumen riset dapat diterima jika nilai loading setiap item atau indikator terhadap variabel yang diukurnya adalah $>0,4$. Jika factor loading suatu item mencapai $>0,5$, maka item tersebut sangat penting dalam menginterpretasikan konstruk yang diukurnya (Hair et al.,2011). 


\subsubsection{Uji Reliabilitas}

Menurut Sugiyono (2016) uji reliabilitas adalah uji yang digunakan untuk menunjukkan bahwa suatu instrumen cukup dapat dipercaya untuk digunakan sebagai alat pengumpul data karena instrumen tersebut sudah baik. Uji ini juga digunakan untuk mengetahui konsistensi alat ukur yang menggunakan skala dalam kuisioner. Reliabilitas berkaitan dengan akurasi dan presisi dari sebuah prosedur pengukuran (Cooper dan Schindler, 2011). Reliabilitas dianggap baik jika beberapa indikator yang berbeda dapat mengukur konstruk yang sama dan memberikan pengukuran yang sama (Neuman, 2006). Reliabilitas diukur dengan nilai cronbach's alpha dengan koefisien cronbach's alpha minimal 0,6 (Hair et al.,2011).

\subsubsection{Analisis Regresi Berganda}

Dalam penelitian ini menggunakan uji analisis regresi berganda yaitu merupakan uji yang digunakan untuk mencari bentuk pengaruh secara parsial dan simultan antara variabel dependen $(\mathrm{Y})$ dan variabel independen $(\mathrm{X})$. Adapun modelnya adalah sebagai berikut:

Keterangan:

$$
Y=\alpha+b_{1} X_{1}+b_{2} X_{2}+b_{3} X_{3}+e
$$

$\mathrm{Y}=$ Keputusan Pemilihan

$\mathrm{X}_{1}=$ Facility Exterior

$\mathrm{X}_{2}=$ Facility Interior

$\mathrm{X}_{3}=$ Other Tangibles

$b=$ Koefisien Prediktor

$\alpha=$ Konstanta

$e=$ Error

\subsubsection{Uji Parsial (Uji T)}

Uji ini digunakan untuk menguji secara parsial yang bertujuan untuk mengetahui pengaruh langsung dari setiap variabel independen $(\mathrm{X})$ terhadap variabel dependen (Y). Uji parsial digunakan untuk mengetahui pengaruh dari masing-masing variabel independen terhadap variabel dependen. Kriteria dalam uji T ini jika nilai probabilitas < 0,5 , maka variabel independen berpengaruh signifikan terhadap variabel dependen. Jika nilai probabilitas $>0,05$, maka variabel independen berpengaruh tidak signifikan terhadap variabel dependen.

\subsubsection{Uji Simultan (Uji F)}

Uji ini digunakan untuk mengetahui pengaruh variabel independen (X) secara simultan atau bersama-sama terhadap variabel dependen (Y). Uji yang digunakan untuk mengetahui apakah variabel independen yang dimasukkan dalam model mempunyai pengaruh secara simultan terhadap variabel dependen (Ghozali, 2012). Kriteria dalam uji F apabila nilai prob. (F-Statistic) $<0,05$, maka seluruh variabel independen secara simultan berpengaruh signifikan terhadap variabel dependen. Jika nilai prob. (FStatistic) $>0,05$, maka seluruh variabel independen secara simultan tidak berpengaruh signifikan terhadap variabel dependen.

\section{Hasil Penelitian dan Pembahasan}

Penelitian ini bertujuan untuk menganalisis pengaruh physical evidence (bukti fisik) terhadap keputusan pemilihan Program Studi Manajemen Fakultas Ekonomi dan Bisnis Universitas Ahmad Dahlan baik secara parsial maupun secara simultan. Setelah peneliti melakukan pengambilan data penelitian dengan metode penyebaran kuisioner terhadap 
mahasiswa Program Studi Manajemen Fakultas Ekonomi dan Bisnis Universitas Ahmad Dahlan sebanyak 200 responden.

Analisis data dilakukan dengan menggunakan software SPSS v.25 dengan mengidentifikasi terlebih dahulu valid atau tidaknya data item pertanyaan yang diajukan kepada responden. Selanjutnya dilakukan uji reliabilitas, barulah dilakukan regresi untuk menjawab hipotesis yang diajukan dalam penelitian ini. Berikutnya dilakukan uji simultan (uji F) untuk mengetahui apakah terdapat pengaruh secara simultan dan uji parsial (Uji T) untuk mengetahui apakah terdapat pengaruh secara parsial.

\subsection{Analisis Deskriptif}

Analisis ini menerangkan tentang data responden seperti jenis kelamin dan usia responden, serta penilaian responden terhadap variabel physical evidence dan keputusan pemilihan produk jasa pendidikan di UAD, dalam hal ini khususnya pada Program Studi Manajemen.

\subsubsection{Jenis Kelamin Responden}

Berdasarkan jenis kelamin responden, terdiri atas dua kelompok yaitu kelompok laki-laki dan perempuan. Hasil analisis data ini diperoleh persentase responden berdasarkan jenis kelamin seperti ditunjukkan pada tabel berikut:

Tabel 1. Jenis Kelamin Responden

\begin{tabular}{c|c|c|}
\hline Jenis Kelamin & Jumlah & Persentase \\
\hline Laki-Laki & 79 & $39 \%$ \\
Perempuan & 121 & $61 \%$ \\
Total & 200 & $100 \%$ \\
\hline
\end{tabular}

Tabel 1 menjelaskan bahwa mayoritas responden yang memilih pendidikan Program Studi Manajemen UAD adalah berjenis kelamin perempuan atau dengan menduduki 61\% sebanyak 121 orang. Sementara sisanya 39\% adalah laki-laki dengan jumlah 79 orang.

\subsubsection{Angkatan Responden}

Berdasarkan angkatan responden, terdiri atas 5 kelompok, yaitu 2016, 2017, 2018, 2019, dan 2020. Dari hasil analisis data diperoleh persentase responden berdasarkan angkatan yang ditunjukkan pada tabel 2 di bawah ini. Dapat dilihat bahwa mayoritas angkatan yang mengisi dan memilih Program Studi Manajemen Fakultas Ekonomi dan Bisnis UAD adalah angkatan 2019 yaitu sebanyak 61\% dengan jumlah 122 orang, sisanya angkatan 2016 sebanyak 0,5\% yaitu 1 orang, angkatan 2017 sebanyak 2,5\% yaitu 5 orang, angkatan 2018 sebanyak 32\% yaitu 64 orang, dan angkatan 2020 sebanyak $4 \%$ yaitu 8 orang.

Tabel 2. Angkatan Responden

\begin{tabular}{c|c|c|}
\hline Angkatan & Jumlah & Persentase \\
\hline 2016 & 1 & $0,5 \%$ \\
2017 & 5 & $2,5 \%$ \\
2018 & 64 & $32 \%$ \\
2019 & 122 & $61 \%$ \\
2020 & 8 & $4 \%$ \\
Total & 200 & $100 \%$ \\
\hline
\end{tabular}




\subsection{Hasil Uji Validitas}

Sebelum dilakukan regresi agar hasil penelitian dapat menghasilkan hasil yang dapat dipercaya, maka dilakukan validasi terhadap item-item pertanyaan kuesioner yang akan disebar kepada pada responden. Item-item tersebut adalah item facility exterior ( 7 item pertanyaan), facility interior (13 item pertanyaan), other tangibles (10 item pertanyaan), dan keputusan pembelian (3 item pertanyaan). Item keputusan pembelian juga dilakukan uji validitas agar dapat diukur sejauh mana ketepatan suatu alat ukur melalui fungsi ukurnya.

Analisis menggunakan uji Kaiser-Meyer Olkin (KMO), uji KMO digunakan untuk mengetahui Measure of Sampling Adequacy (MSA) yang menunjukkan apakah data yang didapatkan sesuai untuk dilakukan analisis faktor. Analisis ini dilakukan pada tiap butir pertanyaan kuisioner. Nilai KMO dan MSA harus sama dengan atau lebih besar dari 0,5 untuk dapat dilakukan analisis faktor menurut Cleff (2019). Hasil uji KMO dan nilai MSA item secara individu dapat dilihat pada tabel berikut:

Tabel 3. Hasil Uji KMO dan Nilai MSA KMO dan Bartlett's Test

\begin{tabular}{|ll|l|}
\hline Kaiser-Meyer-Olkin Measure of Sampling Adequacy & 0,912 \\
\hline Bartlett's Test of Sphericity & Approx. Chi-Square & 3799,8675 \\
& $\mathrm{df}$ & 528 \\
& Sig. & 0,000 \\
\hline
\end{tabular}

Tabel 3 di atas menunjukkan hasil uji KMO dan Bartlett's bahwa nilai KMO sebesar 0,912 dengan signifikansi 0,000. Hal ini dapat disimpulkan bahwa uji analisis faktor telah memenuhi kriteria karena semua sub variabel atau item pengukuran layak sebagai faktor untuk masing-masing variabel yang diukurnya.

Tabel 4 di bawah ini menunjukkan hasil analisis faktor terhadap variabel facility exterior, facility interior, dan other tangibles. Item FE1, FI4, FI11, dan FI12 secara statistik bukan merupakan pembentuk dimensi physical evidence karena terdapat cross loading pada item tersebut yang tidak sesuai dengan kriteria dalam penelitian ini yaitu harus berada di atas 0,5 , sehingga item tersebut dinyatakan tidak valid. Hasil analisis faktor pada konstruk other tangibles dan keputusan memilih program studi manajemen menunjukkan tidak ada item pertanyaan yang dibuang karena semuanya memiliki factor loading di atas 0,5 . 
Tabel 4. Hasil Uji Validitas

\begin{tabular}{|c|c|c|c|c|c|}
\hline \multirow{2}{*}{$\begin{array}{c}\text { Item } \\
\text { Pertanyaan }\end{array}$} & \multicolumn{4}{|c|}{ Komponen } & \multirow{2}{*}{ Keterangan } \\
\hline & 1 & 2 & 3 & 4 & \\
\hline FE2 & & & 0.611 & & Valid \\
\hline FE3 & & & 0.523 & & Valid \\
\hline FE4 & & & 0.707 & & Valid \\
\hline FE5 & & & 0.708 & & Valid \\
\hline FE6 & & & 0.636 & & Valid \\
\hline FE7 & & & 0.549 & & Valid \\
\hline FI1 & 0.632 & & & & Valid \\
\hline FI2 & 0.761 & & & & Valid \\
\hline FI3 & 0.782 & & & & Valid \\
\hline FI5 & 0.559 & & & & Valid \\
\hline FI6 & 0.746 & & & & Valid \\
\hline FI7 & 0.712 & & & & Valid \\
\hline FI8 & 0.547 & & & & Valid \\
\hline FI9 & 0.743 & & & & Valid \\
\hline FI10 & 0.619 & & & & Valid \\
\hline FI13 & 0.605 & & & & Valid \\
\hline OT1 & & 0.555 & & & Valid \\
\hline OT2 & & 0.729 & & & Valid \\
\hline OT3 & & 0.595 & & & Valid \\
\hline OT4 & & 0.555 & & & Valid \\
\hline OT5 & & 0.739 & & & Valid \\
\hline OT6 & & 0.760 & & & Valid \\
\hline OT7 & & 0.528 & & & Valid \\
\hline OT8 & & 0.678 & & & Valid \\
\hline OT9 & & 0.786 & & & Valid \\
\hline OT10 & & 0.680 & & & Valid \\
\hline KMPM1 & & & & 0.808 & Valid \\
\hline KMPM2 & & & & 0.800 & Valid \\
\hline КМРМ3 & & & & 0.637 & Valid \\
\hline
\end{tabular}

\subsection{Hasil Uji Realibiltas}

Setelah item pertanyaan dinyatakan valid, langkah berikutnya adalah menguji reliabilitasnya untuk mengetahui sejauh mana alat ukur dapat memberikan hasil yang konsisten bila digunakan untuk mengukur obyek yang sama dengan alat ukur yang sama. Teknik yang digunakan untuk menilai reliabilitas adalah dengan cronbach's alpha, dengan cara menyebarkan kuesioner kepada mahasiswa Program Studi Manajemen Fakultas Ekonomi dan Bisnis Universitas Ahmad Dahlan. Suatu instrumen dapat dikatakan reliabel jika lebih dari 0,6 (Ghozali, 2012). 
Tabel 5. Hasil Uji Reliabilitas

\begin{tabular}{l|c|c|}
\hline \multicolumn{1}{|c|}{ Variabel } & Cronbach's Alpha & Keterangan \\
\hline Facility Exterior & 0,842 & Reliabel \\
Facility Interior & 0,923 & Reliabel \\
Other Tangibles & 0,877 & Reliabel \\
Keputusan Memilih Program & 0,827 & Reliabel \\
Studi & & \\
\hline
\end{tabular}

Menurut Hair et al., (2011) suatu konstruk dikatakan reliabel jika memberikan nilai lebih besar dari 0,6. Berdasarkan ringkasan hasil uji reliabilitas pada tabel 5, dapat diketahui bahwa nilai cronbach's alpha pada seluruh variabel lebih besar dari 0,6. Dengan demikian semua butir pertanyaan dalam variabel penelitian dapat dikatakan reliabel.

\subsection{Analisis Regresi Berganda}

\subsubsection{Uji Parsial (Uji T)}

Tabel 6. Hasil Uji Parsial

\begin{tabular}{|c|c|c|c|}
\hline \multirow{2}{*}{ Variabel } & \multicolumn{3}{c|}{ Physical Evidence Parsial } \\
\cline { 2 - 4 } & B & T & Sig. \\
\hline Facility Exterior & 0,218 & 7,811 & 0,000 \\
$\mathrm{R}^{2}=0,236$ & & & \\
$\Delta \mathrm{R}^{2}=0,232$ & & & \\
Facility Interior & 0,146 & 9,120 & 0,000 \\
$\mathrm{R}^{2}=0,296$ & & & \\
$\Delta \mathrm{R}^{2}=0,292$ & & & \\
Other Tangibles & 0,187 & 6,865 & 0,000 \\
$\mathrm{R}^{2}=0,192$ & & & \\
$\Delta \mathrm{R}^{2}=0,188$ & & & \\
\hline
\end{tabular}

Hipotesis pertama mengatakan bahwa facility exterior berpengaruh positif terhadap keputusan pemilihan Program Studi Manajemen Fakultas Ekonomi dan Bisnis Universitas Ahmad Dahlan. Hasil ini dibuktikan pada tabel 6 yang menunjukkan bahwa faktor dalam physical evidence dalam dimensi facility exterior memiliki pengaruh positif dan signifikan terhadap keputusan pemilihan Program Studi Manajemen $(\beta=0,146 ; t=$ 7,811; Sig. =0,000). Hal ini menunjukkan hipotesis pertama diterima.

Hipotesis kedua mengatakan bahwa facility interior berpengaruh positif terhadap keputusan pemilihan Program Studi Manajemen Fakultas Ekonomi dan Bisnis Universitas Ahmad Dahlan. Hasil ini dibuktikan pada tabel 6 yang menunjukkan bahwa faktor dalam physical evidence dalam dimensi facility interior memiliki pengaruh positif dan signifikan terhadap keputusan pemilihan Program Studi Manajemen $(\beta=0,218 ; t=$ 9,120; Sig. =0,000). Hal ini menunjukkan hipotesis kedua diterima.

Hipotesis ketiga mengatakan bahwa other tangibles berpengaruh positif terhadap keputusan pemilihan Program Studi Manajemen Fakultas Ekonomi dan Bisnis Universitas Ahmad Dahlan. Hasil ini dibuktikan pada tabel 6 yang menunjukkan bahwa faktor dalam physical evidence dalam dimensi other tangibles memiliki pengaruh positif dan signifikan terhadap keputusan pemilihan Program Studi Manajemen $(\beta=0,187$; $\mathrm{t}=$ 6,865; Sig. $=0,000$ ). Hal ini menunjukkan hipotesis ketiga diterima. 


\subsubsection{Uji Simultan (Uji F)}

Tabel 7. Hasil Uji Simultan

\begin{tabular}{|c|c|c|}
\hline Variabel & \multicolumn{2}{|c|}{ Physical Evidence Simultan } \\
\cline { 2 - 3 } & F & Sig. \\
\hline Keputusan Pemilihan & 33,559 & 0,000 \\
$\mathrm{R}^{2}=0,339$ & & \\
$\Delta \mathrm{R}^{2}=0,329$ & & \\
\hline
\end{tabular}

Hipotesis keempat mengatakan bahwa faktor physical evidence (facility exterior, facility interior, other tangibles) secara simultan berpengaruh signifikan terhadap keputusan pemilihan Program Studi Manajemen Fakultas Ekonomi dan Bisnis Universitas Ahmad Dahlan. Hasil ini dibuktikan pada tabel 7 yang menunjukkan bahwa faktor physical evidence secara simultan memiliki berpengaruh signifikan terhadap keputusan pemilihan Program Studi Manajemen ( $F=33,559$; Sig. $=0,000)$. Hal ini menunjukkan hipotesis keempat diterima.

\subsection{Pembahasan}

4.5.1. Pengaruh Positif Facility Exterior terhadap Keputusan Pemilihan Program Studi Manajemen Fakultas Ekonomi dan Bisnis Universitas Ahmad Dahlan

Hipotesis pertama mengatakan bahwa facility exterior berpengaruh positif terhadap keputusan pemilihan Program Studi Manajemen Fakultas Ekonomi dan Bisnis Universitas Ahmad Dahlan. Hasil pengujian menunjukkan bahwa faktor dalam physical evidence dalam dimensi facility exterior memiliki pengaruh positif dan signifikan terhadap keputusan pemilihan Program Studi Manajemen $(\beta=0,146 ; t=7,811$; Sig. $=$ 0,000 ). Hal ini menunjukkan hipotesis pertama diterima dan mendukung penelitian terdahulu dari Sabrilia et al., (2016) menunjukkan hasil bahwa faktor physical evidence dalam dimensi facility exterior dapat memberi pengaruh positif terhadap keputusan pembelian konsumen di Happy Cow Palasari Bandung.

Adanya dukungan pada pengaruh positif tampilan luar seperti desain atau gambaran atau tampilan luar gedung di lingkungan Program Studi Manajemen menarik. Kemudian, terdapat papan penunjuk yang jelas ketika mahasiswa ingin menuju ke tempat yang dituju. Selanjutnya, terdapat juga lahan parkir di lingkungan Program Studi Manajemen yang cukup memadai dan tertata rapi. Kondisi lingkungan di sekitarnya juga mendukung dalam proses belajar mengajar.

\subsubsection{Pengaruh Positif Facility Interior terhadap Keputusan Pemilihan Program Studi Manajemen Fakultas Ekonomi dan Bisnis Universitas Ahmad Dahlan}

Hipotesis kedua mengatakan bahwa facility interior berpengaruh positif terhadap keputusan pemilihan Program Studi Manajemen Fakultas Ekonomi dan Bisnis Universitas Ahmad Dahlan. Hasil pengujian menunjukkan bahwa faktor dalam physical evidence dalam dimensi facility interior memiliki pengaruh positif dan signifikan terhadap keputusan pemilihan Program Studi Manajemen $(\beta=0,218 ; t=9,120$; Sig. $=$ 0,000). Hal ini menunjukkan hipotesis kedua diterima.

Dengan adanya dukungan pengaruh positif tersebut menunjukkan bahwa terdapat pengaruh tampilan di dalam ruangan seperti fasilitas yang mendukung kegiatan belajar mengajar terhadap pemilihan Program Studi Manajemen Fakultas Ekonomi dan Bisnis Universitas Ahmad Dahlan. Kemudian desain ruangan yang menarik dan memadai, tata ruang yang dapat diaplikasikan sesuai dengan berbagai model kegiatan pembelajaran dan beberapa kondisi ruangan yang cukup mendukung dalam kegiatan belajar mengajar juga menjadi pertimbangan dan alasan calon mahasiswa dalam memilih Program Studi Manajemen. 


\subsubsection{Pengaruh Positif Other Tangibles terhadap Keputusan Pemilihan Program Studi Manajemen Fakultas Ekonomi dan Bisnis Universitas Ahmad Dahlan}

Hipotesis ketiga mengatakan bahwa other tangible berpengaruh positif terhadap keputusan pemilihan Program Studi Manajemen Fakultas Ekonomi dan Bisnis Universitas Ahmad Dahlan. Hasil pengujian menunjukkan bahwa faktor dalam physical evidence dalam dimensi other tangibles memiliki pengaruh positif dan signifikan terhadap keputusan pemilihan Program Studi Manajemen $(\beta=0,187 ; \mathrm{t}=6,865$; Sig. $=$ 0,000). Hal ini menunjukkan hipotesis ketiga diterima.

Hasil yang positif ini juga mendukung bahwa ada faktor lain dalam bukti fisik yang menjadi alasan mahasiswa dalam memilih Program Studi Manajemen seperti adanya kartu tanda pengenal berupa Kartu Tanda Mahasiswa (KTM) yang dapat dijadikan pengenal bahwa mahasiswa tersebut adalah mahasiswa Program Studi Manajemen Fakultas Ekonomi dan Bisnis Universitas Ahmad Dahlan. Selanjutnya terdapat berbagai alat tulis yang mendukung kegiatan belajar mengajar, adanya laporan mengenai tagihan biaya perkuliahan bagi mahasiswa dan orang tua mahasiswa, dan di lingkungan Program Studi Manajemen juga terdapat berbagai laporan mengenai kinerja Program Studi Manajemen yang ditunjukkan dengan prestasi akreditasi, lomba-lomba, dan sebagainya.

Kemudian, dosen dan karyawan juga mengenakan seragam yang menarik yang menunjukkan profesionalitas kerja setiap hari Senin, Selasa, dan Rabu bagi dosen dan setiap hari kerja bagi karyawan di lingkungan Program Studi Manajemen. Program Studi Manajemen juga memiliki situs resmi yang dapat membantu mahasiswa, dosen, dan karyawan dalam berproses baik dalam bidang akademik maupun non akademik.

\subsubsection{Pengaruh Signifikan Physical Evidence secara Simultan terhadap Keputusan Pemilihan Program Studi Manajemen Fakultas Ekonomi dan Bisnis Universitas Ahmad Dahlan}

Hipotesis keempat mengatakan bahwa faktor physical evidence (facility exterior, facility interior, other tangibles) secara simultan berpengaruh signifikan terhadap keputusan pemilihan Program Studi Manajemen Fakultas Ekonomi dan Bisnis Universitas Ahmad Dahlan. Hasil pengujian menunjukkan bahwa faktor physical evidence secara simultan memiliki pengaruh signifikan terhadap keputusan pemilihan Program Studi Manajemen ( $F=33,559$; Sig. $=0,000)$. Hal ini menunjukkan hipotesis keempat diterima.

Dengan adanya pengaruh signifikan pada physical evidence (facility exterior, facility interior, other tangibles) secara simultan terhadap keputusan dalam memilih Program Studi Manajemen berarti setiap mahasiswa di lingkungan Program Studi Manajemen dalam memilih Program Studi Manajemen Fakultas Ekonomi dan Bisnis Universitas Ahmad Dahlan. Berdasarkan tampilan desain luar dan dalam ruangan yang menarik dan memadai, serta beberapa unsur pendukung lain seperti penggunaan seragam pada dosen dan karyawan, situs laman yang informatif, dan fasilitas-fasilitas lain yang mendukung dalam pemilihan Program Studi Manajemen. Hal ini sejalan dengan penelitian yang dilakukan oleh Sabrilia et al., (2016) bahwa secara simultan physical evidence berpengaruh signifikan terhadap keputusan pembelian konsumen di Happy Cow Palasari Bandung. 


\section{Kesimpulan dan Saran}

\subsection{Kesimpulan}

Berdasarkan hasil analisis data dan pembahasannya, maka dapat disimpulkan sebagai berikut:

1. Terdapat pengaruh positif facility exterior terhadap keputusan pemilihan Program Studi Manajemen Fakultas Ekonomi dan Bisnis Universitas Ahmad Dahlan. Hipotesis pertama yang mengatakan facility exterior berpengaruh positif terhadap keputusan pemilihan Program Studi Manajemen Fakultas Ekonomi dan Bisnis Universitas Ahmad Dahlan diterima.

2. Terdapat pengaruh positif facility interior terhadap keputusan pemilihan Program Studi Manajemen Fakultas Ekonomi dan Bisnis Universitas Ahmad Dahlan. Hipotesis kedua yang mengatakan facility interior berpengaruh positif terhadap keputusan pemilihan Program Studi Manajemen Fakultas Ekonomi dan Bisnis Universitas Ahmad Dahlan diterima.

3. Terdapat pengaruh positif other tangibles terhadap keputusan pemilihan Program Studi Manajemen Fakultas Ekonomi dan Bisnis Universitas Ahmad Dahlan. Hipotesis ketiga yang mengatakan other tangibles berpengaruh positif terhadap keputusan pemilihan Program Studi Manajemen Fakultas Ekonomi dan Bisnis Universitas Ahmad Dahlan diterima.

4. Terdapat pengaruh signifikan physical evidence secara simultan terhadap Keputusan Pemilihan Program Studi Manajemen Fakultas Ekonomi dan Bisnis Universitas Ahmad Dahlan. Hipotesis keempat yang mengatakan physical evidence secara simultan berpengaruh signifikan terhadap keputusan pemilihan Program Studi Manajemen Fakultas Ekonomi dan Bisnis Universitas Ahmad Dahlan diterima.

\subsection{Saran}

Berdasarkan kesimpulan di atas, selanjutnya dapat diusulkan saran yang diharapkan akan bermanfaat bagi pemasar produk jasa pendidikan berkaitan dengan pengaruh physical evidence terhadap keputusan pemilihan Program Studi Manajemen yaitu sebagai berikut:

1. Program Studi Manajemen Fakultas Ekonomi dan Bisnis Universitas Ahmad Dahlan dapat mempertimbangkan secara keseluruhan faktor physical evidence mulai dari tampilan di luar ruangan dan segala fasilitasnya, tampilan di dalam ruangan dan segala fasilitasnya, serta faktor tampilan fisik lain yang mendukung dalam pemilihan Program Studi Manajemen karena secara simultan masih terdapat pengaruh terhadap keputusan pemilihan jasa pendidikan Program Studi Manajemen Fakultas Ekonomi dan Bisnis Universitas Ahmad Dahlan.

2. Universitas Ahmad Dahlan dalam hal ini khususnya adalah Program Studi Manajemen Fakultas Ekonomi dan Bisnis dapat lebih memperhatikan bukti fisik di luar ruangan berupa gedung dan taman yang diperindah, fasilitas yang memadai dalam proses kegiatan belajar mengajar, lokasi parkir yang luas, dan segala sarana prasarana yang dapat menjadikan bukti fisik menjadi pertimbangan ketika calon konsumen dalam hal ini calon mahasiswa yang ingin mendaftar di Program Studi Manajemen Fakultas Ekonomi dan Bisnis Universitas Ahmad Dahlan.

3. Program Studi Manajemen Fakultas Ekonomi dan Bisnis Universitas Ahmad Dahlan juga sebaiknya memperhatikan segala tampilan di dalam ruangan dan segala fasilitas yang memadai dan mendukung kegiatan belajar mengajar, alat-alat tulis yang dapat digunakan dalam kegiatan belajar mengajar, penyusunan layout berupa modular yang dapat dirubah sesuai dengan metode yang digunakan dalam kegiatan belajar mengajar, serta kondisi ruangan yang dapat mendukung segala kegiatan belajar mengajar.

4. Program Studi Manajemen juga bisa mengembangkan faktor lain dalam bukti fisik 
seperti situs resmi dan sosial media yang selalu diperbaharui informasinya, kemudian selebaran yang informatif dan mudah diakses oleh calon mahasiswa baru.

\section{Daftar Pustaka}

Adriansyah, R., \& Kartawinata, B. R. (2014). Pengaruh Bauran Pemasaran Jasa terhadap Keputusan Penggunaan pada Konsumen Hotel Posters Bandung. eProceedings of Management, 1(3), 1-20.

Assauri, Sofjan. (2004). Manajemen Pemasaran. Edisi I. Cetakan ke-7. PT. Raja Grafindo Persada

Citrawati, D., \& Sulistiono. (2014). Pengaruh Bauran Pemasaran Jasa terhadap Keputusan Pembelian. Jimkes Jurnal Ilmiah Manajemen Kesatuan, 2(1), 19-28.

Cleff, T. (2019). Applied Statistics and Multivariate Data Analysis for Business And Economics. Springer International Publishing.

Cooper, Donald R., \& Schindler, Pamela S. (2011). Business Research Methods. Mc GrawHill.

Dahl, D. W., Argo, J. J., \& Morales, A. C. (2012). Social Information in the Retail Environment: The Importance of Consumption Alignment, Referent Identity, and Self-Esteem. Journal of Consumer Research, 38(5),860-871.

Ghozali, Imam. (2012). Aplikasi Analisis Multivariate dengan Program IBM SPSS 20. Badan Penerbit-Universitas Diponegoro.

Hair, J. F. Jr., Black, W. C., Babin, B. J., Anderson, R. E., \& Tatham, R. L. (2011). Multivariate Data Analysis. Person Practice Hall.

Ibad, S., Arifin, R., \& Priyono, A. A. (2018). Pengaruh Bauran Pemasaran Jasa (Product, Price, Place, Promotion, Process, People, dan Physical Evidence) terhadap Keputusan Pembelian (Studi Kasus pada Jasa Transportasi CV King Tour And Travel). Jurnal Ilmiah Riset Manajemen, 7(2), 167-179.

Irpansyah, M. A., Ramdan, A. M., \& Danial, R. D. M. (2019). Kredibilitas dan Kekuatan Selebgram dalam Meningkatkan Minat Beli pada Toko Online di Instagram. COSTING: Journal of Economic, Business and Accounting, 2(2), 248-255.

Kopp, S. W., \& Langenderfer, J. (2014). Protecting Appearance and Atmospherics: Trade Dress as a Component of Retail Strategy. Journal of Public Policy \& Marketing, 33(1), 34-48.

Kotler, P., \& Keller, K. L. (2016). Marketing Management 15th Ed. Pearson Education, Inc.

Mercelina Suratman, J. P., Wilopo, W., \& Sunarti, S. (2018). Pengaruh Bauran Pemasaran Jasa terhadap Keputusan Berkunjung (Studi pada Pengunjung Taman Rekreasi Sengkaling). Jurnal Administrasi Bisnis, 57(2), 12-20.

Misbahuddin dan Hasan, I. (2014). Analisis Data Penelitian dengan Statistik. Bumi Aksara.

Neuman, W. L. (2006). Social Research Methods Qualitative and Quantitative Approach. Upper Saddle River Pearson.

Suryana Hendrawan (Pengaruh Physical Evidence terhadap Keputusan Pemilihan Program Studi

Manajemen Fakultas Ekonomi dan Bisnis Universitas Ahmad Dahlan) 
Sabrilia, T., Andari, R., \& Abdullah, T. (2016). Pengaruh Physical Evidence terhadap Keputusan Pembelian Konsumen di Happy Cow Palasari Bandung (Survey pada Konsumen di Happy Cow Palasari Bandung). Gastronomi Tourism Journal, 2(2), 180-188.

Sarashadi, G., \& Dewi, A. S. (2018). Pengaruh Penggunaan Vlogger Endorser pada Iklan dalam Membentuk Niat Beli Konsumen. Jurnal Bisnis dan Manajemen (Journal of Business and Management), 18(1), 41-52.

Shimp, Terence. (2014). Komunikasi Pemasaran Terpadu dalam Periklanan dan Promosi. Salemba Empat.

Sugiyono. (2016). Metode Penelitian Kuantitatif, Kualitatif, dan R\&D. Alfabeta.

Swastha, Basu. (2009). Azas Azas Marketing. Penerbit Liberty.

Swastha, Basu. (2008). Manajemen Pemasaran Modern. Penerbit Liberty.

Wulan, W. S., Mawardi, M. K., \& Pangestuti, E. (2016). Pengaruh Bauran Pemasaran Jasa terhadap Keputusan Pembelian Serta Dampaknya terhadap Kepuasan Pelanggan (Studi pada Restoran Kayu Manis Tuban). Jurnal Administrasi Bisnis, 38(2), 176-183.

Zeithaml, V. A., \& Bitner, M. J. (2000). Service Marketing: Integrating Customer Focus Across The Firm, Second Edition Hill. McGraw.

Zhao, T., \& Tseng, C. L. (2007). Flexible Facility Interior Layout: A Real Options Approach. The Journal of the Operational Research Society, 58(6), 729-739. 